\title{
Water Resources and Sustainability Assessment Based on Group AHP-PCA Method: A Case Study in the Jinsha River Basin
}

\author{
Jian-Lan Zhou ${ }^{1, * \mathbb{O}}$, Qin-Qin $\mathrm{Xu}^{2}$ and Xian-Yong Zhang ${ }^{3}$ \\ 1 Key Lab Image Process \& Intelligent Control, Huazhong University of Science \& Technology, Wuhan 430074, \\ China \\ 2 School of Automation, Huazhong University of Science \& Technology, Wuhan 430074, China; \\ m201872595@hust.edu.cn \\ 3 School of Civil Engineering \& Mechanics, Huazhong University of Science \& Technology, Wuhan 430074, \\ China; zhang_xianyong@hust.edu.cn \\ * Correspondence: zhou_jianlan@hust.edu.cn; Tel.: +86-027-8754-0210
}

Received: 24 November 2018; Accepted: 15 December 2018; Published: 19 December 2018

\begin{abstract}
There is a necessity to assess water resources sustainability for its development and management. However, achievements in water resources and sustainability assessment and specific assessment indicators are limited in current research. A comprehensive index system and the importance priorities of indicators are provided in this study. The group AHP-PCA (group analytic hierarchy process and principal component analysis) method is proposed to calculate the importance priorities and reduce the dispersion existing in traditional group AHP. A case study is conducted to assess the water resource sustainability of four provinces where the Jinsha River flows and the results are consistent with the experience and knowledge of water resources management and actual situations of these provinces. Further work is still needed for more applications.
\end{abstract}

Keywords: water resources and sustainability assessment; indicator importance; dispersions; Group AHP-PCA; Jinsha River basin

\section{Introduction}

Water resources sustainability is defined as the design and management of a water resources system to make a good contribution to present and future goals for a society, which ensures ecological, environmental and hydro-logical integrity [1]. The assessment and improvement of sustainability and capacity of water resources can help humans to predict the future and sustainable development of water resources [2]. A comprehensive system and weight ranks of indicators are the core focuses of the assessment, and measures should be taken to develop the system and rank the indicators [3-5].

Many studies have been conducted in the assessment of water resources sustainability [6-12]. Koop et al. [6] proposed a critical review of a city blueprint approach to evaluate the sustainability of water resources management. Giacomoni and Berglund [7] carried out a case study to evaluate adaptive demand management for urban water resources sustainability by a complex adaptive modeling framework. Xu et al. [8] evaluated Yellow River Water resources with the water resources system dynamics model. Zeng et al. [9] studied the sustainable utilization of water resources under uncertain conditions by using the scenario-based stochastic optimization method based on the Laplace criterion. Peterson et al. [10] assessed sustainable water resources in Minnesota's (USA) Twin Cities Metropolitan Area based on the watershed characteristics approach. Hernandez-Bedolla et al. [11] developed different indicators to assess the availability of water using an integrated water resources management approach. Ni et al. [12] performed four different scenarios to assess the water sustainability of 
Chongming Island. Although the aforementioned researchers assessed the sustainability of water resources from different viewpoints and methods, they did not explore this problem in a hierarchical way or provide the importance priorities of indices.

The analytic hierarchy process (AHP) proposed by Saaty [13] is widely applied in assessment and is a structured process in which the relevant factors of a decision are arranged in a hierarchic structure $[14,15]$. AHP is successfully used as the priority weight calculation method of a decision support system in water resources management. Experts evaluated the social, environmental, economic and institutional components which may affect the sustainability of water resources and understood the main causality of regional water systems $[2,4,16]$. Although the AHP method is used in water sustainability assessment, it is better to consult a group of experts to avoid bias and groups make better decisions than individuals, because groups are accepted to be more knowledgeable than individuals [15]. Hence, the standard AHP has been extended as group AHP in group decisions; for example, in the determination of the optimal treatment technology for chemical pollution accidents, selection of suppliers of irrigation equipment, selection of fire prevention measures for steel structures [17-19].

Group AHP is able to synthesize the views of experts, and has been widely used in group decision making, although it still has some limitations. When the group judgment matrix is too dispersed, the obtained geometric mean value cannot be used to synthesize experts' judgments [20]. Therefore, there is a need to take dispersion into account to achieve consistency [21]. To overcome this problem, $\mathrm{Lin}$ and $\mathrm{Lu}[21]$ used linear mixed models based on the regression approach to estimate the decision weights of AHP instead of using the geometric means for aggregating experts' judgments. However, the linear mixed model assumes that the errors associated with pairwise comparison judgments are normally distributed after undertaking the logarithm, hence a more convenient and rigorous method should be conducted for making inferences about variance components.

In comparison, principal component analysis (PCA) is a widespread technique for data analysis that relies on the covariance matrix of the analyzed data [22], and it is a rigorous computational process that involves no assumptions [23]. PCA provides the weights needed to get the new variable that best explains the variation in the whole dataset in a certain sense. This new variable including the defining weights is called the first principal component [24]. PCA is one of the most popular methods to help researchers in the visualization, exploration and mining of large amounts of data $[25,26]$. In particular, we obtain the weights of experts by the first principal component to adjust group judgment matrix and thus effectively reduce dispersion.

In the current research work, the importance ranking of water resources and sustainability assessment indicators is lacking and there is no solution for excessive dispersion in group AHP. To address these two issues, the aim of this study is to rank the importance of water resources and sustainability assessment indicators by the proposed group AHP-PCA method which can eliminate the dispersions, and then prioritize the sustainability levels of four provinces (regions) where the Jinsha River flows. In the evaluation process, we first construct the group judgment matrix of experts by using the group AHP method, and then PCA is used to compute expert weights. Second, the weights of the experts and the indicators are combined to construct a new group judgment matrix then provide priorities to the criteria/indicators by traditional AHP. Finally, we evaluate four provinces (regions) where the Jinsha River flows based on multiplied scores. One novelty of this study is that we reconstruct the group judgment matrix in the evaluation process which differs from previous research. The other is that although some researchers have conducted serious work related to water resources sustainability assessment by various methods, there are scarce studies that solve the dispersion problem existing in the group judgment matrix. By contrast, this study provides the group AHP-PCA method to reduce dispersion.

The rest of this study is organized as follows: in Section 2, the basic concepts of group AHP and PCA are summarized, and the combination of them is proposed. Section 3 introduces the application of this method in a case study of water resources sustainability in the Jinsha River 
basin. In Section 4, simulation to verify the effect of group AHP-PCA is performed. Discussion and management recommendations, as well as the limitations are presented in Section 5. In Section 6, we present the conclusions.

\section{Methodology}

\subsection{Selection of Indicators}

It has been acknowledged that the first step of assessment is the establishment of the index system [27]. In general, the index system includes three levels which are called the goal, criterion layer and index layer, respectively. There is lots of literature screening the criteria related to water resources and sustainability assessment [28,29]. Through that work, we conclude that water resources and sustainability assessment is based on criteria from the dimensions of economic efficiency, social equity, environmental conservation and maintenance capacity. The indicators that adequately cover the aforementioned criteria should be suitable to measure the sustainability of water use and management. Moreover, the diversity of water resources makes the indicators of sustainability assessment different; for example, an urban water resources system, river basin water resources system, groundwater resources system, and national water resources system, should all have their specific sustainability assessment indicators [30-33]. Many water resources systems are beyond the borders of local communities, often due to upstream-downstream linkages within catchments and river basin. It has therefore been widely acknowledged that if it is necessary to remove towards a higher spatial level, the river basin is the most appropriate unit for assessment [34]. There is also literature on water resources and sustainability assessment in the basin [35]. Thus, we choose the Jinsha River basin in China as a case study of this study.

Considering the aforementioned reference works, we choose 16 indicators presented by Kang and Lee [16], which are related to 4 criteria and have a certain generality and independence simultaneously in the assessment framework. These indicators are illustrated in Table 1. Although we accepted the descriptions of almost every indicator, we redefined instream flow management because of lack of data. On the other hand, one of the main concerns of instream flow management is supplement flow, which can be regulated through reservoir capacity, so we evaluated this indicator in a reservoir capacity/population [36].

Table 1. The indicators of four criteria (adapted from [16]).

\begin{tabular}{|c|c|c|}
\hline Criteria & Indicators & Computational Expressions \\
\hline $\begin{array}{c}\text { Maintenance } \\
\text { capacity }\end{array}$ & $\begin{array}{c}\text { Education level (EL) } \\
\text { Investment in culture and } \\
\text { education (ICE) } \\
\text { Investment in water resources (IWR) } \\
\text { Water saving (WS) }\end{array}$ & $\begin{array}{c}\text { Number of persons graduated from high school/population } \\
\text { Amount of investment in culture and education/population } \\
\text { Amount of investment in water resources/total area } \\
\text { Amount of water saved/population }\end{array}$ \\
\hline Social equity & $\begin{array}{c}\text { Industrial water use (IWU) } \\
\text { Sewage coverage (SC) } \\
\text { Potable water system coverage (PWSC) } \\
\text { Instream flow management (IFM) } \\
\text { Agricultural water use (AWU) }\end{array}$ & $\begin{array}{l}\text { Industrial water use in a watershed/total industrial } \\
\text { water use } \times 100 \\
\text { Number of persons using sewage/population } \times 100 \\
\text { Number of persons using potable water } \\
\text { system/population } \times 100 \\
\text { Reservoir capacity/population } \\
\text { Area of irrigated paddy fields/total paddy fields } \times 100\end{array}$ \\
\hline $\begin{array}{l}\text { Economic } \\
\text { efficiency }\end{array}$ & $\begin{array}{c}\text { Water-quality management (WQM) } \\
\text { Supplementary water resources (SWR) } \\
\text { Water intake (WI) } \\
\text { Economic benefits (EB) }\end{array}$ & $\begin{array}{l}\text { Achievement rate of objective water quality/annual product } \\
\text { per person } \\
\text { Amount of supplementary water resources/population } \\
\text { Amount of annual water intake/annual product per person } \\
\text { Annual economic benefits from water resources/population }\end{array}$ \\
\hline
\end{tabular}




\subsection{Group Analytic Hierarchy Process (AHP)}

Water resources and sustainability assessment is a multi-criteria decision-making problem involving multiple evaluation indicators, and under this scenario, AHP is widely used to explore the importance of indicators [37]. However, because of the subjective and random knowledge and experience limitations of the designated experts, the results obtained by traditional AHP may be too subjective [38]. The subjectivity of expert evaluation can be reduced by using group decision-making method [19]. Therefore, water resources sustainability is evaluated by using group AHP.

Group AHP can divide the assessment problem in a hierarchical form with goal at the top, and criteria and indicators at the lower layer. At each level, according to certain rules, the element of each level is compared one by one, and then the group judgment matrix is established. By calculating the maximum eigenvalue and the corresponding orthogonal eigenvector of each expert judgment matrix in the group decision process, the element weights to each expert are obtained [13]. By synthesizing the element weights of each expert by geometric means, we can get the weight of each level element. Group AHP has strong maneuverability and can fully consider the experience and knowledge of experts and the preference of experts.

\subsection{Principal Component Analysis (PCA)}

PCA is a widely used statistical technique for unsupervised dimensionality reduction, which can detect coherent patterns more clearly [39]. PCA projects a dataset $\bar{A}$ into an orthonormal base, which is defined as a set of eigenvectors of the covariance matrix of $\overline{\mathbf{A}}$. This orthonormal base is oriented in the directions that provide the maximum variance of $\overline{\mathbf{A}}$ to carry the most relevant information. The dimensionality reduction principle is the representation of the dataset $\overline{\mathbf{A}}$ in terms of covariance matrix eigenvectors, which are called principle components. In general, few principal components are needed to account for the majority of variance of the original dataset. According to PCA's principle of maximum variance, the eigenvector with the largest eigenvalue is the most representative component for the data with the largest quantity of information which is called first principle component [40].

\subsection{The Group AHP-PCA}

Group AHP is widely used in group decision processes, however, it has some deficiencies whereby if the group judgment is too dispersed, i.e., a single pairwise comparison is not close to geometric mean of the group comparisons, then the resulting geometric mean may not be used as the representative judgment for the group. Dispersion may affect the indicator priorities and could violate pareto optimality. PCA can be used to obtain experts' weights then adjust group judgment matrix to reduce dispersion.

Water resources and sustainability assessment can be decomposed into goal at the top, criteria and indicators in the lower level based on the group AHP method. Based on this hierarchy structure, experts compare the importance of indicators one by one on a scale of nine [41] and then the group judgment matrix is established. Because of the symmetry of the judgment matrix, a new judgment matrix is generated by taking the triangular elements of the original group judgment matrix in the group AHP. We take the comparison value of experts in the group judgment matrix as the observation value of the dataset processed by PCA and the number of experts as the dimension of the dataset processed by PCA. Thus, we can obtain expert weights from the eigenvector with the largest eigenvalue. In order to convert the discrete evaluation value to the continuous value, PCA determines the logarithm of the new matrix and then calculates the covariance of the logarithmic matrix to obtain the eigenvalues and eigenvectors of the covariance matrix. Finally, by standardizing the eigenvector, we can get the weight of each expert.

The expert weights obtained from PCA can be used to build the comprehensive judgment matrix. Correspondingly, the covariance matrix required by the PCA method can be obtained from the group judgment matrix of the group AHP method. After the synthesized group judgment matrix is 
constructed by combining a group decision matrix with expert weights, we can obtain the weight of each indicator by the solution of traditional AHP. The detailed process is explained in Figure 1, which includes the following 9 steps.

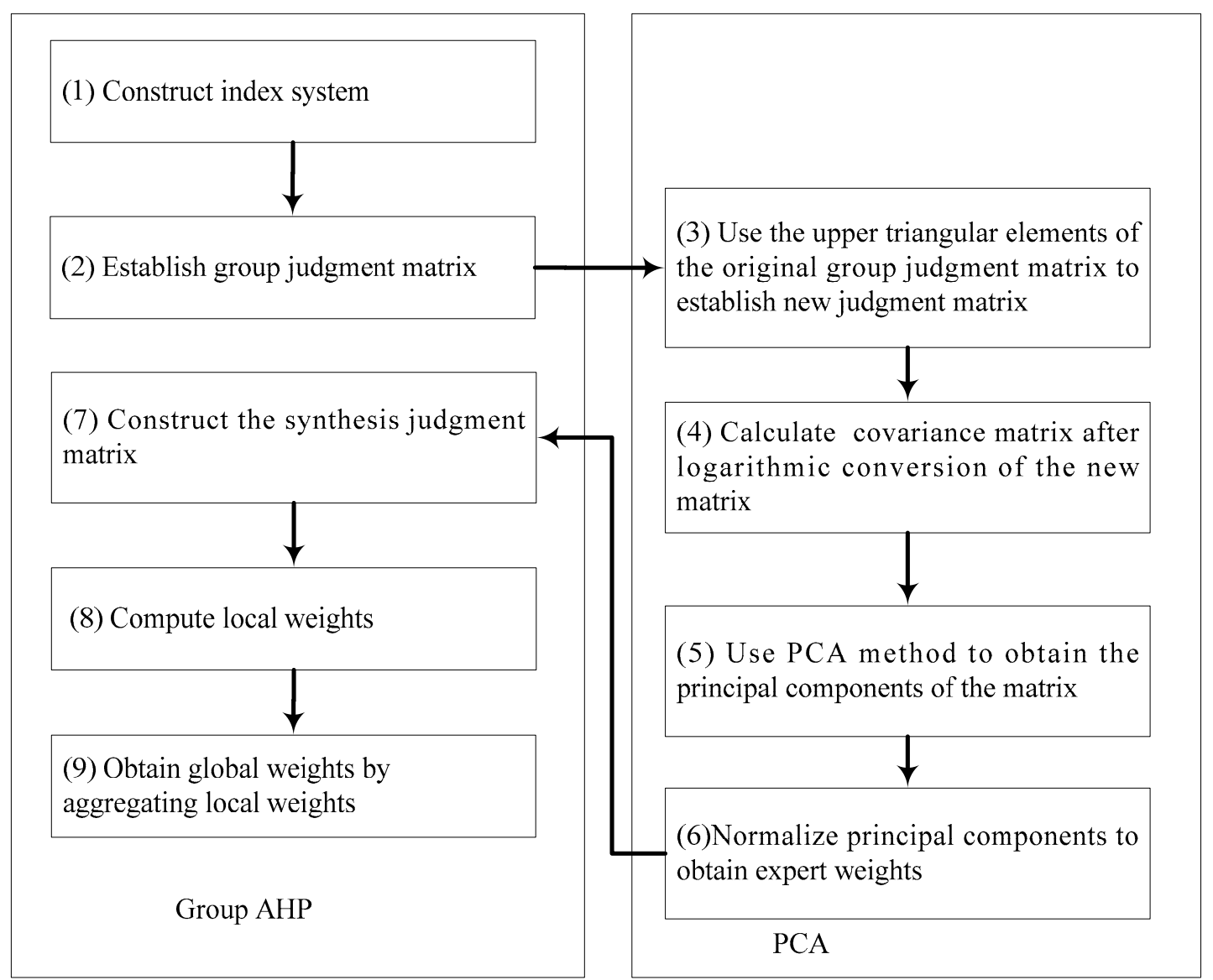

Figure 1. The calculation process of the group analytic hierarchy process and principal component analysis (group AHP-PCA) method.

Step 1: Describe the assessment problem in a hierarchical form, which includes the goal at the top, and criteria and indicators in the lower layer (Figure 2).

Step 2: Establish the group judgment matrix. It conducts the relative importance comparisons of the pairwise criteria/indicators in the same level in a mode from downward to upward. The comparisons are made on a scale of nine to show how many times more important one criterion/ indicator is over another criterion/indicator according to a particular goal/criterion at the upper level. This semantic scale consists of verbal scales that are associated with numerical values (Table 2) [13]. Supposing $\mathrm{n}$ indicators are compared and $\mathrm{m}$ experts participate in the judgment. The group judgment matrix $\mathbf{A}$ can be defined as Table 3. The lower triangular part of matrix $\mathbf{A}$ is completed with the reciprocal value of the upper triangular part, such as: $a_{i j}^{k}=\frac{1}{a_{j i}^{k}}$ or $a_{i j}^{k} \cdot a_{j i}^{k}=1$, where $a_{i j}^{k}$ is the $k$-th expert's judgment on the relative importance of $i$-th indicator and the $j$-th indicator. 


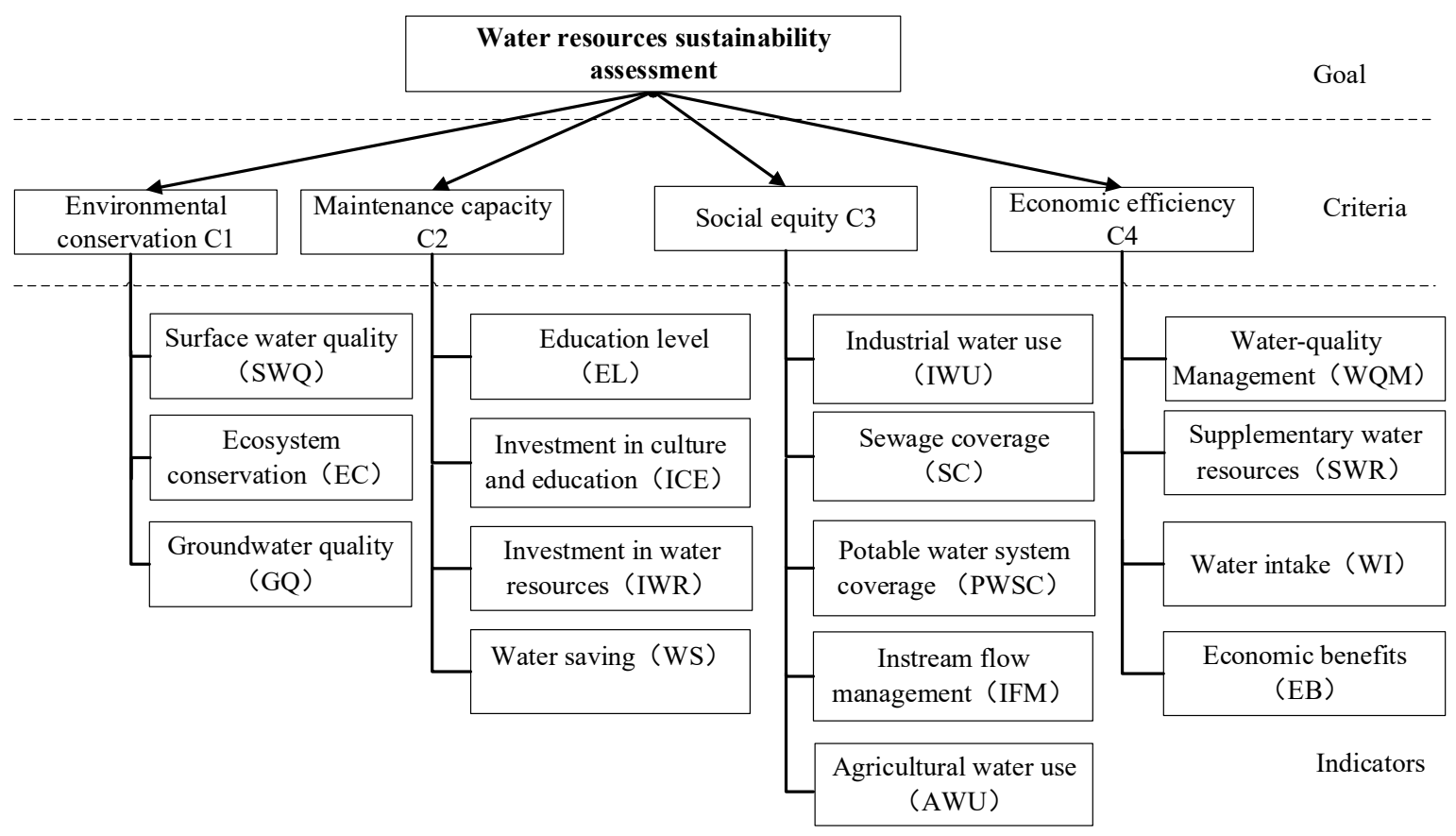

Figure 2. The hierarchy for water resources and sustainability assessment indicators (adapted from [16]).

Table 2. Scale measurement for AHP (adapted from [13]).

\begin{tabular}{cl}
\hline Numerical Values & Definition \\
\hline 1 & Index $x_{i}$ is as important as index $x_{j}$ \\
3 & Index $x_{i}$ is slightly more important than index $x_{j}$ \\
5 & Index $x_{i}$ is obviously more important than index $x_{j}$ \\
7 & Index $x_{i}$ is strongly more important than index $x_{j}$ \\
9 & Index $x_{i}$ is extremely more important than index $x_{j}$ \\
$2,4,6,8$ & Middle value of the above adjacent judgments \\
\hline
\end{tabular}

Table 3. The group judgment matrix A. $a_{i j}{ }^{k}$ is the $k$-th expert judgment between $i$ and $j . n$ is element number and $\mathrm{m}$ is expert number.

\begin{tabular}{ccccc}
\hline $\mathbf{A}$ & $x_{\mathbf{1}}$ & $x_{2}$ & $\ldots$ & $x_{n}$ \\
\hline$x_{1}$ & 1 & $\left(a_{12}^{1} \ldots a_{12}^{k} a_{12}^{m}\right)$ & $\ldots$ & $\left(a_{1 n}^{1} \ldots a_{1 n}^{k} a_{1 n}^{m}\right)$ \\
$x_{2}$ & $\left(a_{21}^{1} \ldots a_{21}^{k} a_{21}^{m}\right)$ & 1 & $\ldots$ & $\left(a_{2 n}^{1} \ldots a_{2 n}^{k} a_{2 n}^{m}\right)$ \\
$\ldots$ & $\ldots$ & $\ldots$ & $\ldots$ & $\ldots$ \\
$x_{n}$ & $\left(a_{n 1}^{1} \ldots a_{n 1}^{k} a_{n 1}^{m}\right)$ & $\left(a_{n 2}^{1} \ldots a_{n 2}^{k} a_{n 2}^{m}\right)$ & $\ldots$ & 1 \\
\hline
\end{tabular}

Step 3: Construct the new matrix. Use the elements above the main diagonal line of group judgment matrix $\mathbf{A}$ to construct the new matrix $\widetilde{\mathbf{A}}$, the number of experts as the dimension of $\widetilde{\mathbf{A}}$, and the comparison values of the criteria/indicators of the experts as the elements of $\widetilde{\mathbf{A}}$.

$$
\widetilde{\mathbf{A}}=\left(\begin{array}{cccc}
a_{12}^{1} & \ldots & a_{12}^{k} & a_{12}^{m} \\
\ldots & \ldots & \ldots & \ldots \\
a_{(n-1) n}^{1} & \cdots & a_{(n-1) n}^{k} & a_{(n-1) n}^{m}
\end{array}\right)
$$

Step 4: Calculate the logarithm of the new matrix $\widetilde{\mathbf{A}}$ to obtain $\overline{\mathbf{A}}$, and then the covariance matrix $\mathbf{B}$ can be obtained by computing the covariance of $\overline{\mathbf{A}}$. 


$$
\mathbf{B}=\operatorname{cov}(\overline{\mathbf{A}})
$$

Step 5: Based on the the PCA maximum variance principle, the expert weights can be obtained from the first principal components by normalizing the maximum eigenvalue and corresponding eigenvector of the covariance matrix.

$$
\mathbf{B w}=\lambda_{\max } \mathbf{w}
$$

where $\lambda_{\max }$ is the maximum eigenvalue, $\mathbf{w}$ is the eigenvector, and $\mathbf{B}$ is the covariance matrix.

Step 6: The comprehensive value of group judgment $\mathrm{G}$ can be obtained by the expert weights scalar product $\overline{\mathbf{A}}$ calculated as Equation (3).

$$
\mathbf{G}=\bar{A} \mathbf{w}
$$

Step 7: The elements of $\mathbf{G}$ are regarded as the upper triangular elements of the synthesis matrix $\mathbf{L}$ in turn. According to the reciprocal properties of the judgment matrix, the lower triangular elements of the synthesis matrix are obtained, shown as:

$$
\left(\begin{array}{cccc}
1 & g_{12} & \ldots & g_{1 n} \\
\frac{1}{g_{12}} & 1 & \ldots & g_{2 n} \\
\ldots & \ldots & \ldots & \ldots \\
\frac{1}{g_{1 n}} & \frac{1}{g_{2 n}} & \ldots & 1
\end{array}\right)
$$

Step 8: The weight vector is calculated by the traditional AHP and normalized to obtain the final weight vector through the way as Equation (4).

$$
\mathbf{L w}=\lambda_{\max } \mathbf{w}
$$

Step 9: The global weights of indicators can be obtained as:

$$
\mathbf{W}_{G}=\mathbf{w}_{C} \mathbf{w}_{I}
$$

where $\mathbf{W}_{G}$ represents the global weights of indicators, $\mathbf{w}_{C}$ represents the weights of criteria and $\mathbf{w}_{I}$ represents the local weights of indicators.

\section{Case Study}

\subsection{Study Area}

The Jinsha River basin in China is selected as a case study to verify the application of the group AHP-PCA method in the assessment of water resources sustainability. The Jinsha River basin flows through Qinghai, Tibet, Sichuan and Yunnan which are four provinces (regions) evaluated in this study. The total area is $483,000 \mathrm{~km}^{2}$, and the length is $2318 \mathrm{~km}$. The basin is located from $90^{\circ}$ to $105^{\circ} \mathrm{E}$ and from $24^{\circ}$ to $36^{\circ} \mathrm{N}$ in the upper reaches of the Yangtze River. In the basin, four well known dams such as Xiangjia Dam, Xiluodu Dam are constructed for flood control, water supply, and hydropower generation. The average rainfall in the study basin is about $960 \mathrm{~mm}$ [42]. Due to the increase in population and industrialization, the demands for municipal and industrial water, instream flow, and environmental and recreational water have increased in the basin.

\subsection{Data Collection}

The data sources for this study are depicted as Table A1. Most of the data are directly obtained from websites of government departments. All the raw data are for the year of 2016, which are shown as Table A2. 


\subsection{Survey}

In this study, a questionnaire survey was used to collect the data needed by the application of hybrid group AHP and PCA. The survey was designed and conducted to determine indicator weights and importance priorities for assessment topics. The quantitative data were collected from 5 experts in the related fields whose profiles are shown in Table 4 . The experts were asked to compare 4 main criteria and 16 indicators in the scope of this study.

Table 4. Profiles of 5 experts. Sources are derived from questionnaires in Appendix C.

\begin{tabular}{ccccc}
\hline ID & Gender & Working Seniority & Profession & Education \\
\hline 1 & Male & 15 & Manager in environmental conservation & Master \\
2 & Female & 10 & Professor in water resources management & Doctor \\
3 & Male & 17 & Researcher in social equity & Bachelor \\
4 & Female & 15 & Researcher in water resources development & Master \\
5 & Male & 20 & Professor in economics & Doctor \\
\hline
\end{tabular}

\subsection{Application in the Jinsha River Basin Sustainability Assessment}

The following are the steps to apply the Group AHP-PCA method in water sustainability assessment in the Jinsha River basin.

Step 1: Establish hierarchy structure. We decompose the problem into a hierarchy structure consisting of goal, criteria, and indicators. For convenience of calculation, indicator abbreviations are used to represent these elements shown in Figure 2

Step 2: Construct group judgment matrix. Experts need to determine the relative importance of each element in the hierarchy. Each element is pairwise compared with other elements at the same level, with respect to a criterion/indicator at a higher level based on a scale of nine, shown as Table 2 . For the criterion layer, we obtain group judgment matrix shown as Table 5.

Table 5. Group judgment matrix between criteria with respect to the goal. These data are judgments on 4 criteria provided by the five aforementioned experts.

\begin{tabular}{ccccc}
\hline & $\mathrm{C}_{1}$ & $\mathrm{C}_{2}$ & $\mathrm{C}_{3}$ & $\mathrm{C}_{4}$ \\
\hline $\mathrm{C}_{1}$ & 1 & $(7,3,1,1,3)$ & $(1,3,3,1,5)$ & $(7,1,3,5,1)$ \\
$\mathrm{C}_{2}$ & & 1 & $\left(\frac{1}{3}, \frac{1}{5}, \frac{1}{7}, 1, \frac{1}{3}\right)$ & $\left(1, \frac{1}{3}, \frac{1}{5}, 1, \frac{1}{7}\right)$ \\
$\mathrm{C}_{3}$ & & & 1 & $(7,1,1,3,5)$ \\
$\mathrm{C}_{4}$ & & & & 1 \\
\hline
\end{tabular}

Step 3: Calculate the weights of experts by using PCA. The above diagonal elements of the group judgment matrix of the criterion layer are used as elements of the new matrix in turn, and the new matrix is obtained as the following:

$$
\left(\begin{array}{ccccc}
7 & 3 & 1 & 1 & 3 \\
1 & 3 & 3 & 1 & 5 \\
7 & 1 & 3 & 5 & 1 \\
\frac{1}{3} & \frac{1}{5} & \frac{1}{7} & 1 & \frac{1}{3} \\
1 & \frac{1}{3} & \frac{1}{5} & 1 & \frac{1}{7} \\
7 & 1 & 1 & 3 & 5
\end{array}\right)
$$

Step 4: Calculate the covariance matrix after the logarithm conversion of the new matrix. Normalize the principal eigenvector of the covariance matrix, the weights of the experts for respect

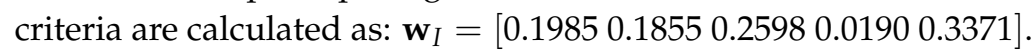


Step 5: The synthesized group judgment matrix in the criterion layer, shown as Table 6, is constructed by the original group judgment matrix combined with the expert weights. The final weights of the four criteria can be obtained by the method of traditional AHP as: $\mathbf{w}_{C}=$ [0.4449 0.0883 0.3155 0.1512]. Figure A1 is the circle correlation of PCA for the four criteria.

Table 6. Synthesized group judgment matrix in the criterion layer.

\begin{tabular}{cccccc}
\hline & $\mathrm{C}_{1}$ & $\mathrm{C}_{2}$ & $\mathrm{C}_{3}$ & $\mathrm{C}_{4}$ & Weight \\
\hline $\mathrm{C}_{1}$ & 1 & 3.2359 & 3.2389 & 2.7856 & 0.4449 \\
$\mathrm{C}_{2}$ & $\frac{1}{3.2359}$ & 1 & 0.2718 & 0.3759 & 0.0883 \\
$\mathrm{C}_{3}$ & $\frac{1}{3.2389}$ & $\frac{1}{0.2718}$ & 1 & 3.5722 & 0.3155 \\
$\mathrm{C}_{4}$ & $\frac{1}{2.7856}$ & $\frac{1}{0.3759}$ & $\frac{1}{3.5722}$ & 1 & 0.1512 \\
\hline
\end{tabular}

Step 6: The same way as the aforementioned method; we calculate the weights of the indicators under each criterion, which are depicted as: $\mathbf{w}_{C 1}=[0.4871,0.0869,0.2519]$, $\mathbf{w}_{C 2}=[0.0936,0.2594,0.3648,0.2822], \mathbf{w}_{C 3}=[0.3851,0.1911,0.0913,0.0463,0.2543], \mathbf{w}_{C 4}=$ $[0.4145,0.2900,0.1791,0.0854]$ The weight of each element should be multiplied by a weight of the higher element to obtain the global weight to sort the indicators. Combined with all the results, we obtain the global weights of all indicators for the sustainability assessment of water resources. We also recalculate the global weights and assign ranks by using the traditional group AHP method for comparison, and the results obtained by both methods are shown in Table 7.

Step 7: The global weights of 16 indicators in the Jinsha River Basin have been obtained from Table 7. We can calculate the final scores of water resources and sustainability assessment of four provinces through which the Jinsha River passes according to Equation (A6) [16] and the results are shown as Table 8.

$$
\mathrm{D}=\sum_{i=1}^{16} w_{i} d_{i}
$$

where D represents the final scores of water resources sustainability, $\mathbf{w}_{i}$ represents the global weight of the indicator, $d_{i}$ represents the normalized data of the indicator.

Table 7 shows us the global weights and the rank of the indicators. The results for the criterion level, the weights of environmental conservation, maintenance capacity, social equity and economic efficiency are $0.4449,0.0883,0.3155$ and 0.1513 , respectively. According to the ranks presented above, it can be easily derived that the five most important indicators are surface water quality, industrial water use, groundwater quality, water-quality management and agricultural water use. From Table 8, we can also see that Sichuan province gains the highest score 0.3002 on water sustainability, followed by Yunnan province, Tibet region and Qinghai province, whose scores are $0.2215,0.2075$ and 0.1799 , respectively. 
Table 7. The synthesis results of the assessment. These data are the results of expert judgment calculated by the proposed method or the traditional group AHP method.

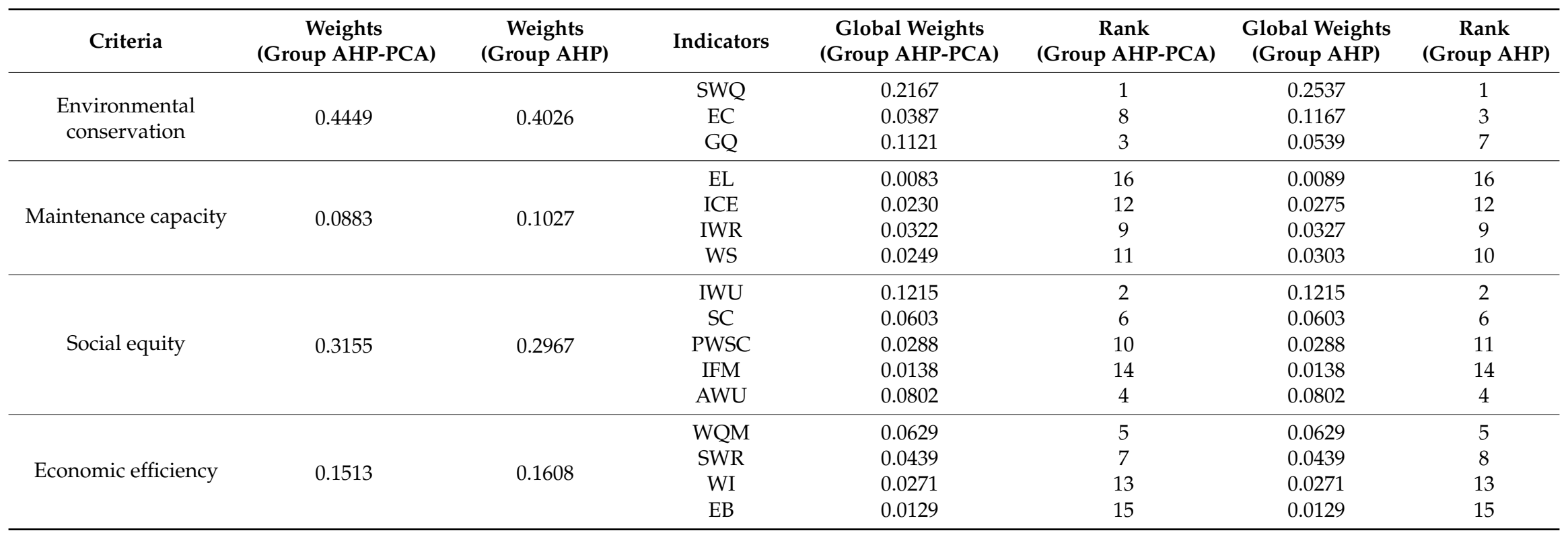


Table 8. Normalized data of 16 indicators.

\begin{tabular}{|c|c|c|c|c|c|}
\hline Indicators & Global Weights & Sichuan & Yunnan & Qinghai & Tibet \\
\hline SWQ & 0.2167 & 0.2330 & 0.2580 & 0.2425 & 0.2665 \\
\hline $\mathrm{EC}$ & 0.0387 & 0.1919 & 0.0814 & 0.3487 & 0.3780 \\
\hline GQ & 0.1121 & 0.2500 & 0.2500 & 0.2500 & 0.2500 \\
\hline EL & 0.0083 & 0.2542 & 0.2203 & 0.2712 & 0.2542 \\
\hline ICE & 0.0230 & 0.1798 & 0.2360 & 0.2785 & 0.3057 \\
\hline IWR & 0.0322 & 0.5390 & 0.4005 & 0.0392 & 0.0213 \\
\hline WS & 0.0249 & 0.1873 & 0.2081 & 0.1872 & 0.4174 \\
\hline IWU & 0.1215 & 0.6889 & 0.2605 & 0.0321 & 0.0185 \\
\hline SC & 0.0603 & 0.2940 & 0.2614 & 0.3168 & 0.1278 \\
\hline PWSC & 0.0288 & 0.0178 & 0.0276 & 0.0651 & 0.8895 \\
\hline IFM & 0.0138 & 0.8551 & 0.0959 & 0.0370 & 0.0120 \\
\hline AWU & 0.0802 & 0.5063 & 0.3417 & 0.0646 & 0.0874 \\
\hline WQM & 0.0629 & 0.2437 & 0.2373 & 0.2342 & 0.2848 \\
\hline SWR & 0.0439 & 0.1733 & 0.1449 & 0.4580 & 0.2237 \\
\hline WI & 0.0271 & 0.2105 & 0.2472 & 0.0518 & 0.4904 \\
\hline $\mathrm{EB}$ & 0.0129 & 0.2336 & 0.3232 & 0.3434 & 0.0998 \\
\hline \multicolumn{2}{|c|}{ Final Scores } & 0.3002 & 0.2215 & 0.1799 & 0.2057 \\
\hline
\end{tabular}

\section{Dispersion-Based Simulation}

We conduct the simulation to verify the effect of group AHP-PCA on the concern that it is inappropriate to adopt the geometric mean to assemble the opinions wherein exists excessive dispersion. We define a few variables in which $m$ represents number of experts, $n$ represents the number of criteria/indicators being compared with each other and $t$ represents the dispersion degree. If dispersion is generated by one pairwise judgment, we define the dispersion degree $t=1$, if dispersion is caused by two pairwise judgments, we define the dispersion degree $t=2$, and so on. In other words, the dispersion degree $t$ can be determined by the number of pairwise judgments which result in dispersion made by either one expert across different criteria/indicators or different experts across the same criterion/indicator.

To capture dispersion variation among the traditional AHP and the proposed method, we define $\mathrm{d}$ and $\mathrm{d}(\mathrm{PCA})$ as the dispersion of group judgment matrix in the traditional AHP method and the proposed method, respectively. Dispersion is calculated as Equation (A6) [20].

$$
S_{G}\left(x_{1}, \ldots, x_{n}\right)=S_{G}\left(x_{[1, n]}, \ldots, x_{[n, n]}\right)=\left(\bar{x}_{G} / \bar{x}_{n 1, n}^{G}\right)^{2 n 1 / n}
$$

where $S_{G}$ represents the sample geometric dispersion, $\left(x_{[1, n]}, \ldots, x_{[n, n]}\right)$ are the order statistics corresponding to the sample $\left\{x_{k}, k=1, \ldots, n\right\}$, i.e., $x_{[h, n]} \leq x_{[k, n]}$ if $h \leq k, \bar{x}_{G}$ is the sample geometric mean, $n 1$ is a value for which $x_{[k, n]} \leq \bar{x}_{G}$ for $k=1, \ldots, n 1 . \bar{x}_{n 1, n}^{G}$ represents the geometric mean of the sample from $n 1$ to $n$.

The simulation is carried out from two aspects: one is when the dispersion degree is constant; we increase the number of elements in the group judgment matrix to observe the fluctuation of dispersion of both methods with fixed experts in each round of simulation. The other is that we change the dispersion degree to observe the fluctuation of dispersion of both methods with fixed experts and the number of elements in each round of simulation.

Under the first scenario, there are 3 experts who evaluate the 4 criteria, seen as Figure $3 \mathrm{a}$ and Table 9. First, it assumes that only one expert always makes the pairwise judgment of the element tuple $(1,2)$ from $(3,3,3)$ to $(9,3,3)$, and we compute the dispersion of both methods by Equation (A6), respectively. In the same way, $d$ and $d(P C A)$ are recalculated to obtain a series of points when $n$ ranges from 4 to 8 . In each round of simulation, the dispersion degree and the number of experts keep constant and only the element tuple $(1,2)$ produces dispersion. Through the simulation, we obtain two broken lines which represent the dispersion fluctuations made by both judgment matrices. 
We change the number of experts to do the same calculation in other rounds of the simulation, depicted in Figure $3 b-f$. As the results indicate, d(PCA) is obviously smaller than $d$, which has no business with n; thus, this shows that the dispersion of the judgment matrix addressed by group AHP-PCA is obviously reduced. When the number of experts is changed, the same result can be obtained from the broken line diagram.

Table 9. Initial matrix. These data in this matrix are simulation data which represent 3 experts' initial judgment on 4 pairwise compared elements.

\begin{tabular}{cccc}
\hline 1 & $(3,3,3)$ & $(5,5,5)$ & $(5,5,5)$ \\
\hline 1 & $\left(\frac{1}{3}, \frac{1}{3}, \frac{1}{3}\right)$ & $\left(\frac{1}{5}, \frac{1}{5}, \frac{1}{5}\right)$ \\
& & $\left(\frac{1}{7}, \frac{1}{7}, \frac{1}{7}\right)$ \\
& & 1 \\
\hline
\end{tabular}

Under the second scenario, there are 9 experts who evaluate the 7 criteria (Figure 3), seen as Figure $4 \mathrm{a}$ and Table 10. First, this assumes that the pairwise judgment of the element tuple $(1,2)$ change from $(3,3,3,3,3,3,3,3,3)$ to $(9,3,3,3,3,3,3,3,3)$ which produces dispersion and $t=1$. By change the pairwise judgments of the element tuples, the dispersion degree ranges from 1 to 6 with fixed number of experts and elements, and we calculate the dispersions made by both methods. To further verify the results, the number of experts and elements are different in 6 rounds of simulation. In each round, we set the combination of the two parameters of $m(9,10,11)$ and $n(7,8)$, depicted in Figure 4. In the case of the diversity of dispersion degrees, the dispersion of the group judgment matrix after PCA treatment is obviously reduced, which further proves our conclusion.

In summary, the results of the simulation show that the group AHP-PCA method can solve the problem by the reassignment of expert weights to modify the dispersed group judgment matrix; otherwise, a set of pairwise comparisons cannot be aggregated directly because of the excessive dispersion in the traditional group AHP. 

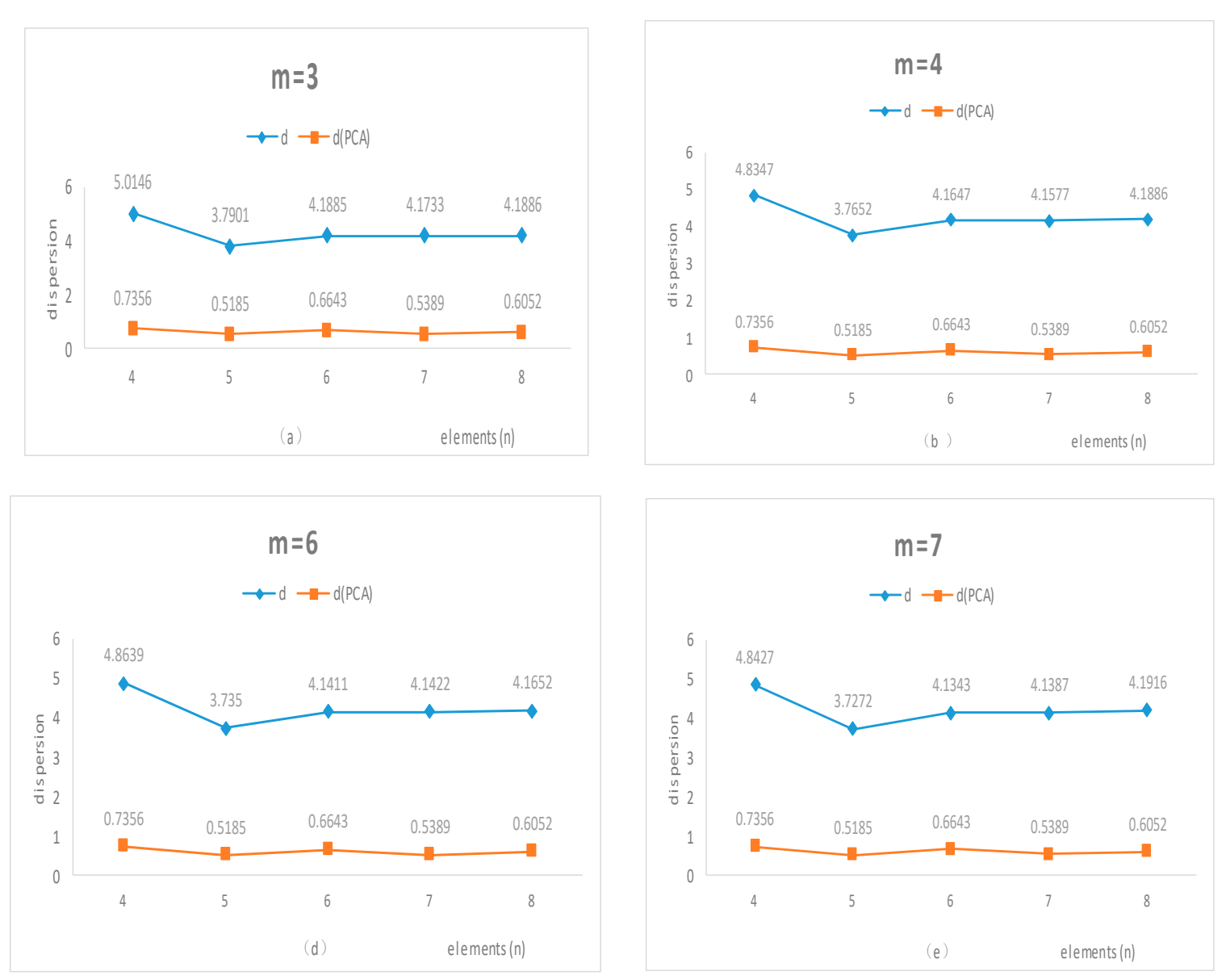
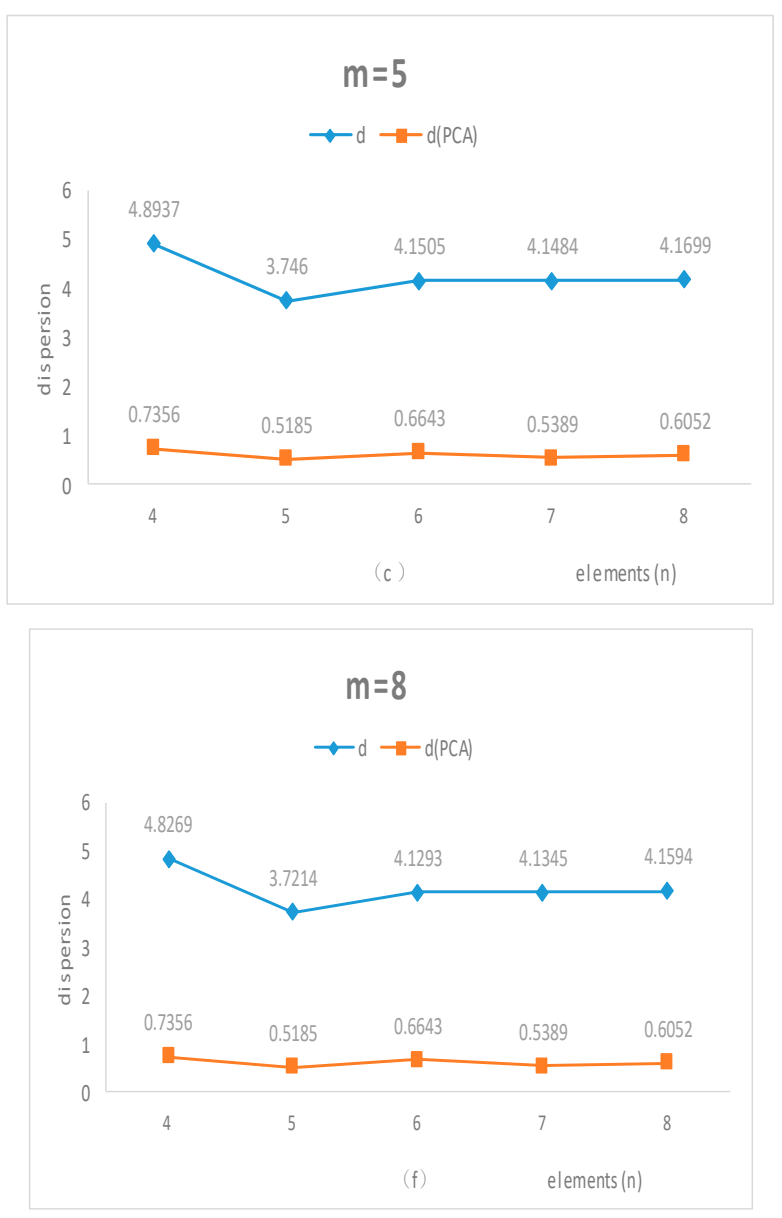

Figure 3. The broken lines of dispersion with element increase, wherein $m$ represents the number of elements shown in the subfigures (a)-(f). 

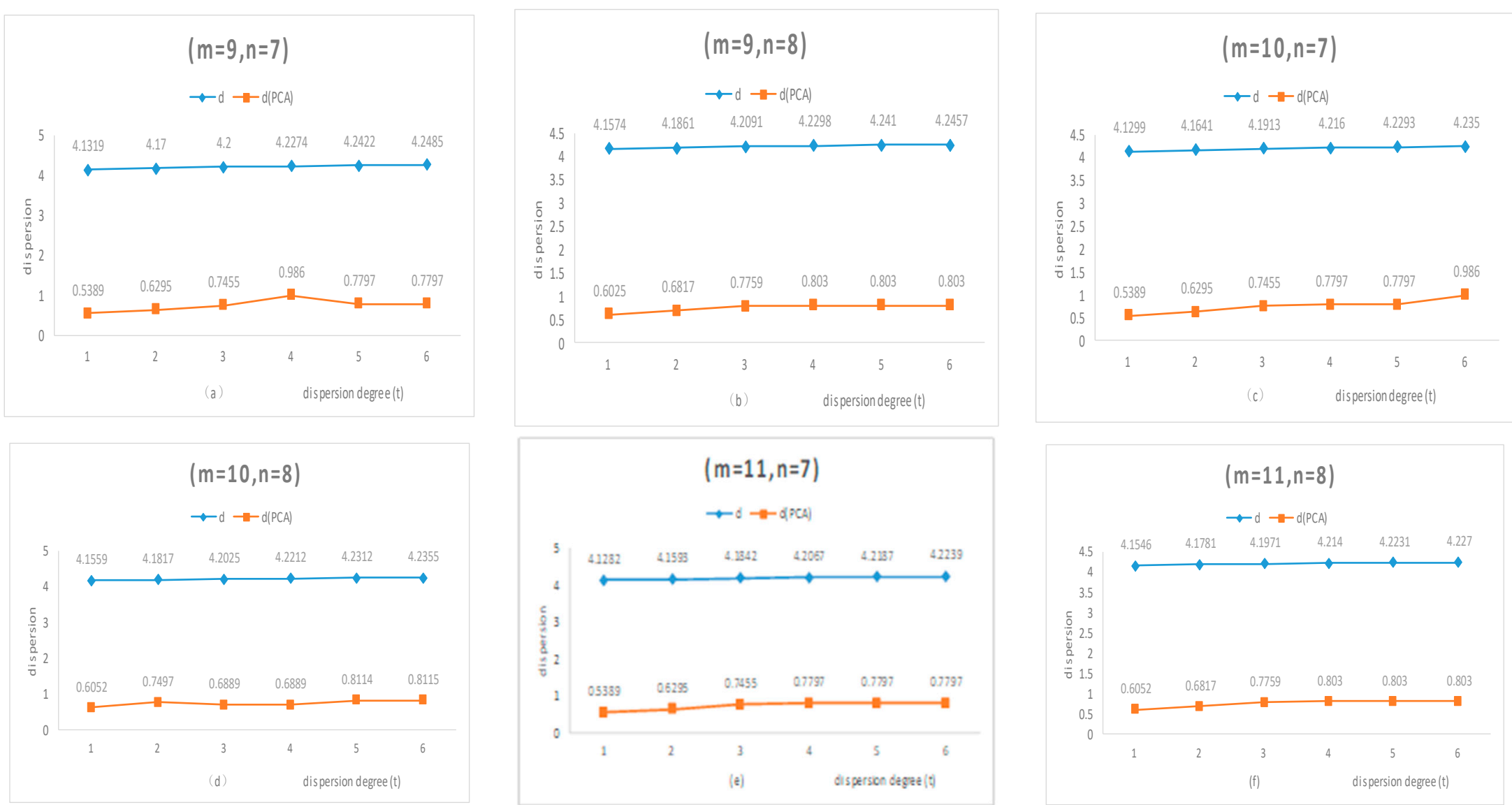

Figure 4. The broken lines of dispersion with dispersion degree increase, wherein $\mathrm{m}$ and $\mathrm{n}$ vary in the subfigures $(\mathbf{a})-(\mathbf{f})$. 
Table 10. Initial matrix. These data in this matrix are simulation data which represent 9 experts' initial judgments on 7 pairwise compared elements.

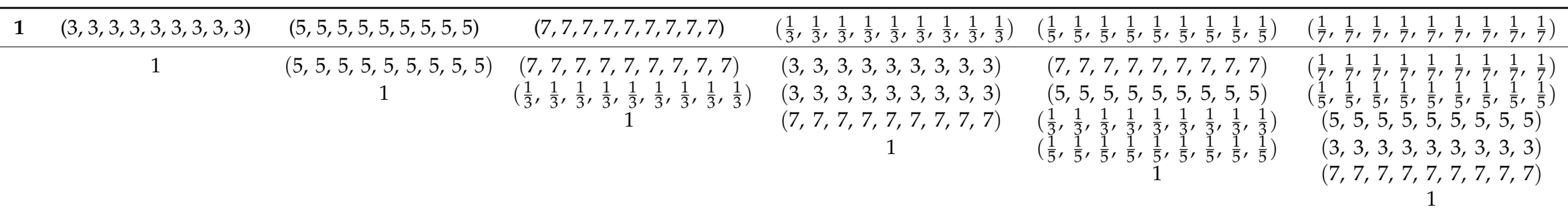




\section{Discussion}

The traditional group AHP method may violate the pareto optimality principle and cannot use the geometric mean to aggregate the judgments for excessive dispersion. Thus, it is reasonable to adopt the group AHP-PCA method to reduce dispersion, which modifies the group judgment matrix by changing the weights of the experts who join in the decision, which has been verified in the previous section. Compared with the previous studies that ignored the dispersion problem in the group AHP [17-19], this study proposed the group AHP-PCA method to reduce the dispersion whose validity was proved by the simulation results. Furthermore, we ranked the importance of water resources and sustainability assessment indicators, which was not done by previous studies.

From Table 7, we can see the difference from the traditional AHP results; the weight of the criterion layer calculated by the Group AHP-PCA method has been changed; for example, the weight of environmental conservation has been increased to 0.4449 from 0.4026 . The ranks of ecosystem conservation and groundwater quality change are obvious in the two methods. The immediate reason for this change is the transformation of the group judgment matrix. Table 5 indicates that the pairwise comparisons $(1,2)$ and $(1,4)$ have a large geometric dispersion which, therefore, leads to a large dispersion on the group judgment. Thus, PCA is used to reduce the dispersion by calculating the weight of the experts to adjust the original group judgment matrix, which changes the global weights and final ranks of the indicators. The root cause of this change is expert 1, whose career led him to have a preference for environmental conservation in the comparison of these indicators, and led him to rate this far higher than other indicators. Traditional AHP believes that the weights of experts are equal; by contrast, the proposed method can adjust the weights of experts to modify the group judgment matrix which can weaken the preference influence of expert 1 in group decision-making. This leads to a significant change in the ranks of ecosystem conservation and groundwater quality while other indicators remain basically unchanged.

In this study, an achievement is the application of the group AHP-PCA method to test its performance over the Jinsha River basin, as can be seen from Table 8, surface water quality has the largest weight. Qinghai and Tibet rate higher on surface water quality than Sichuan and Yunnan, but their final scores are lower. The reason is that the diversity of the scores on this indicator for these four provinces is small. This indicates that the high score of only one major indicator does not necessarily lead to the high total score, which are the comprehensive results of all indicators. That means, not only do the global weights of indicators, but also the diversity of the data, obtain different results.

Sichuan obtains the highest score and Qinghai is opposite from Table 8, which is satisfied with the fact that Sichuan has the largest amount of water resources and the highest level of modernization among the four provinces. In recent years, the economy of Sichuan province has developed healthily and rapidly, the industrial structure has been transformed, and the investment in water resources and instream flow management are obviously superior to the other three provinces (regions) which result in the highest total score in Sichuan province. From Table 8, investment in water resources, industrial water use and agricultural water use in Qinghai province are the lowest among the four provinces. For these three indicators, we give recommendations, respectively. In the light of the investment in water resources, it is suggested to establish diversified, multi-level and multi-channel water conservancy investment entities and strive for the support of the state in capital. The government should establish a fund for water conservancy construction and do a good job in the operation and policy charges for water resources. It is useful to introduce more domestic and foreign capital to further broaden the sources of funds for infrastructure construction such as water supply and hydropower. As for industrial water use, it is encouraged to improve the utilization of water resources in industrial enterprises and increase the use of recycled water. It is necessary to optimize the allocation of water resources and increase the efficiency and effectiveness of water use. The water conservancy department should formulate preferential policies to encourage enterprises to use recycled water, strengthen technological development, and pilot promotion of reclaimed water sources, and encourage 
enterprises to build new rainwater collection pools and other projects. As for agricultural water use, the government needs to strengthen the management and maintenance of farmland and water conservancy projects, improve the research and promotion of new technologies and methods for agricultural irrigation, and conduct research on irrigation systems and irrigation quotas.

From a practical perspective, it is envisaged that the group AHP-PCA method can provide effective guidance for water resources study where future water-related policies should perhaps focus on the four criteria as a priority in decreasing order of importance with the environmental conservation at the highest, social equity at the second, the economic efficiency at the third and the maintenance capacity at last rank. Importantly, the final results of the group AHP-PCA method can help to prioritize the provinces on which to focus. For example, in light of Table 8, it is construed that better plans for water resources sustainability development in Qinghai Province are needed.

We propose the group AHP-PCA method to take numerous opinions into consideration for the assessment of water resources sustainability. The empirical study in the Jinsha River basin shows that the proposed method is suitable and effective. However, the proposed method has its limitations, of which the index system can be various and it is not possible to establish a universal index system for all types of basins. Secondly, since the last step of our method uses the traditional AHP method whose limitation is that it is inappropriate when the number of criteria/indictors is relatively larger $(n$ $>10$ ) in each round of computation [43].

This study addresses the dispersion problem in the traditional group AHP. The large excessive dispersion represents the obvious disagreements among decision makers. In that case, the geometric mean cannot be used to aggregate the experts' judgments so that the group AHP may violate the pareto optimality principle. In the previous studies, scholars would prefer to revise the experts' judgments or wipe off them that lead to dispersion. Oppositely, there is no need to demand experts to revise their judgements and each judgement in the group can be taken into account by the proposed method in this study. Moreover, the simple weighted geometric mean is used to aggregate expert judgments with the objective weights by the proposed method.

\section{Conclusions}

This study establishes an integrated index system for water resources and sustainability assessment in the Jinsha River basin. As a systematic and organized approach, the group AHP-PCA method is proposed for the assessment. Group AHP is used to obtain the construction of the target hierarchy and group judgment matrix; PCA is used to compute expert weights and eliminate the dispersion; then the final group judgment matrix is obtained by multiplying the group judgment matrix with the expert weight vector. We can see that the group AHP-PCA method not only collects the opinions of different experts but also reduces group judgment dispersion. We simulate from two aspects to verify the effectiveness of this method and then the Jinsha River basin is selected as a case to calculate and rank its water resources sustainability in four provinces. The results show that the highest index that influences water resources and sustainability assessment is surface water quality followed by groundwater and industry water use. Amongst four provinces (regions), Sichuan province has the highest total score on water resources sustainability.

The index system proposed in this study can help the stakeholders to comprehensively consider multiple dimensions of water resources sustainability, whilst the method provides the insights to properly integrate experts with various levels of knowledge and experiences and rationally measures both quantitative and qualitative indicators. The evaluation results are relatively intuitive and rational, at least to some degree.

Considering the final comprehensive evaluation results, water resources sustainability can be improved and optimized according to the rank of specific indicators and areas. Assessment of the water resources sustainability should be conducted regularly to guide the development and management of water resources. In all, we hope this study can provide insights and guidelines for guiding 
the government to formulate, adopt, evaluate or update the existing water resources sustainable management policies and standards.

As we proved that the proposed method can reduce dispersion in group AHP in the simulation section. Thus, the proposed method can be used to reconstruct the group judgment matrix to reduce dispersion when there is too excessive a dispersion in the judgment matrix in the other assessment system. Although the group AHP-PCA method is a powerful method in the assessment field, it also has some limitations. When the number of experts is large, the reduction of dispersion is not obvious by using the proposed method. Thus, more efforts are needed to make this approach more universal.

Author Contributions: Conceptualization, J.-L.Z.; Methodology, J.-L.Z. and Q.-Q.X.; Software, Q.-Q.X.; Validation, J.-L.Z. and Q.-Q.X.; Formal Analysis, J.-L.Z. and Q.-Q.X.; Investigation, J.-L.Z. and Q.-Q.X.; Resources, X.-Y.Z.; Data Curation, Q.-Q.X.; Writing-Original Draft Preparation, Q.-Q.X.; Writing-Review \& Editing, J.-L.Z.; Visualization, J.-L.Z.; Supervision, J.-L.Z.; Project Administration, J.-L.Z.; Funding Acquisition J.-L.Z. and X.-Y.Z.

Funding: This research was funded by [the CRSRI Open Research Program] grant number [CKWV2018481/KY], [the National Key Research and Development Program of China] grant number [2017YFC0805100] and [the Fundamental Research Funds for the Central Universities] grant number [2017KFYXJJ178].

Conflicts of Interest: The authors declare no conflict of interest.

\section{Appendix A}

In this study, comparisons made by experts can be considered similar to observations in PCA, while each of the experts can be considered as a dimension of the dataset. PCA provides the weights needed to get the new variable that best explains the variation in the whole dataset. This new variable including the defining weights is called the first principal components. Thus, the weight of experts can be obtained by the first principal components. The proof procedures of step 5 are as follows:

The goal of PCA in this study is to find a vector with the maximum variance of the experts' evaluation projection values on the vector, which is a weight vector of the experts. Take elements

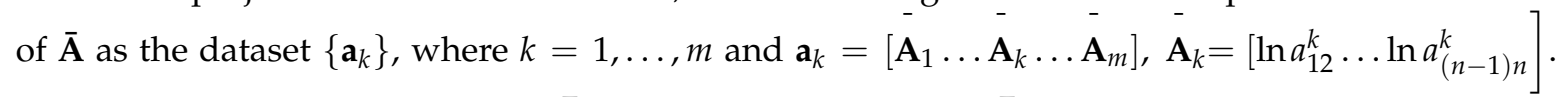
Suppose a matrix $\mathbf{U}=\left[\mathbf{u}_{l}\right]$, where $\mathbf{u}_{l}^{T}=\left[u_{1 l} \ldots u_{k l} \ldots u_{m l}\right]$ and $\mathbf{u}_{l}^{T} \mathbf{u}_{l}=1 . \overline{\mathbf{A}}$ is the mean of the dataset expressed as:

$$
\overline{\mathbf{a}}=\frac{1}{m} \sum_{k=1}^{m} a_{k}
$$

The variance of the projection data is calculated as:

$$
\frac{1}{m} \sum_{k=1}^{m}\left(u_{l}^{T} a_{k}-u_{l}^{T} \bar{a}\right)=\mathbf{u}_{l}^{T} \mathbf{B} \mathbf{u}_{l}
$$

Here, $\mathbf{u}_{l}^{T} \mathbf{a}_{k}$ is the projection of data onto the vector $\mathbf{u}_{l}$ whose mean is $\mathbf{u}_{l}^{T} \mathbf{a}^{-} \mathbf{u}_{l}^{T} \mathbf{B} \mathbf{u}_{l}$ represents the variance of the projection data. $\mathbf{B}$ represents the covariance matrix of the data and the calculation method of $\mathbf{B}$ is:

$$
\mathbf{B}=\frac{1}{m} \sum_{k=1}^{m}\left(a_{k}-\bar{a}\right)\left(a_{k}-\bar{a}\right)^{T}
$$

To find the largest variance of the projection data, the problem is estimated in Equation (A4).

$$
\max \left(\mathbf{u}_{l}^{T} \mathbf{B} \mathbf{u}_{l}\right)
$$

The process of maximization must prevent the limitation $\left\|\mathbf{u}_{l}\right\| \rightarrow \infty$, which is satisfied with the premise $\mathbf{u}_{l}^{T} \mathbf{u}_{l}=1$. To enforce this constraint, we introduce the Lagrangian multiplier $\lambda$, thus, Equation (A4) can be replaced by maximizing Equation (A5).

$$
\mathbf{u}_{l}^{T} \mathbf{B} \mathbf{u}_{l}+\lambda\left(1-\mathbf{u}_{l}^{T} \mathbf{u}_{l}\right)
$$


Compute the derivate about $\mathbf{u}_{l}$ for Equation (6), we obtain the extreme point subject to Equation (A6).

$$
\mathbf{B} \mathbf{u}_{l}=\lambda \mathbf{u}_{l}
$$

where $\mathbf{u}_{l}$ is an eigenvector of $\mathbf{B}$ and $l=1, \ldots, m$. We can obtain the variance by pre- multiplying $\mathbf{B} \mathbf{u}_{l}$ with $\mathbf{u}_{l}^{T}$, see in Equation (A7).

$$
\mathbf{u}_{l}^{T} \mathbf{B} \mathbf{u}_{l}=\lambda
$$

According to Equation (A7), the variance of the projection data will reach the maximum value when we set $\mathbf{u}_{l}$ to be equal to the eigenvector with the largest eigenvalue $\lambda$. In other words, we can get the maximum variance of the projection data by finding the eigenvector corresponding to the maximum eigenvalue of the covariance $\mathbf{B}$ of the dataset.

\section{Appendix B}

\begin{tabular}{|c|c|c|}
\hline Indicators & Data Sources & Website Remarks \\
\hline \multirow{4}{*}{ SWQ } & http://www.schj.gov.cn/ & \multirow{4}{*}{ Four provincial environmental protection offices } \\
\hline & http://www.ynepb.gov.cn/ & \\
\hline & http://www.qhepb.gov.cn/ & \\
\hline & http://www.xzep.gov.cn/ & \\
\hline EC & http://www.stats.gov.cn/ & National Bureau of Statistic of China \\
\hline \multirow{4}{*}{ GQ } & http://www.schj.gov.cn/ & \multirow{4}{*}{ Four provincial environmental protection offices } \\
\hline & http://www.ynepb.gov.cn/ & \\
\hline & http://www.qhepb.gov.cn/ & \\
\hline & http://www.xzep.gov.cn/ & \\
\hline EL & \multirow{4}{*}{ http:/ / www.stats.gov.cn/ } & \multirow{4}{*}{ National Bureau of Statistic of China } \\
\hline ICE & & \\
\hline IWR & & \\
\hline WS & & \\
\hline IWU & http://www.mwr.gov.cn/ & Ministry of Water Resources of China \\
\hline SC & \multirow{3}{*}{ http://www.stats.gov.cn/ } & \multirow{3}{*}{ National Bureau of Statistic of China } \\
\hline PWSC & & \\
\hline IFM & & \\
\hline AWU & http:/ /www.mwr.gov.cn/ & Ministry of Water Resources of China \\
\hline WQM & http://www.stats.gov.cn/ & National Bureau of Statistic of China \\
\hline SWR & http://www.mwr.gov.cn/ & Ministry of Water Resources of China \\
\hline $\mathrm{WI}$ & \multirow{2}{*}{ http:/ / www.stats.gov.cn/ } & \multirow{2}{*}{ National Bureau of Statistic of China } \\
\hline EB & & \\
\hline
\end{tabular}

Table A1. Data sources. 
Table A2. Raw data of 16 indicators for the year 2016.

\begin{tabular}{|c|c|c|c|c|c|}
\hline Indicators & Unit & Sichuan & Yunnan & Qinghai & Tibet \\
\hline SWQ & Compliance rate & $87.41 \%$ & $96.8 \%$ & $91 \%$ & $100 \%$ \\
\hline $\mathrm{EC}$ & $\begin{array}{l}\text { Area classified as the ' } 1 \text { st' }^{\prime} \text { grade on the } \\
\text { eco-nature index/total area }\end{array}$ & $17.21 \%$ & $7.3 \%$ & $31.27 \%$ & $33.9 \%$ \\
\hline GQ & Compliance rate & $100 \%$ & $100 \%$ & $100 \%$ & $100 \%$ \\
\hline EL & $\begin{array}{c}\text { Number of persons graduated from high } \\
\text { school/population }\end{array}$ & 0.0060 & 0.0052 & 0.0064 & 0.0060 \\
\hline ICE & $\begin{array}{c}\text { Investment amount/population } \\
\text { (Yuan per person) }\end{array}$ & 701 & 920 & 1086 & 1192 \\
\hline IWR & $\begin{array}{c}\text { Investment amount/total area } \\
\text { (Yuan/hectare) }\end{array}$ & 12242 & 9098 & 891 & 484 \\
\hline WS & $\begin{array}{l}\text { Water saving irrigation area/population } \\
\text { (hectare per person) }\end{array}$ & 3.41 & 3.79 & 3.41 & 7.60 \\
\hline IWU & Billion $\mathrm{m}^{3} /$ total industrial water use $\times 100$ & 68.89 & 26.05 & 3.21 & 1.85 \\
\hline SC & $\begin{array}{l}\text { Sewage discharge/population number } \\
\left.\text { ( } \mathrm{m}^{3} \text { per person }\right)\end{array}$ & 42.70 & 37.96 & 46.00 & 18.56 \\
\hline PWSC & $\mathrm{m}^{3} /$ per person & 2843.31 & 4391.67 & 10375.95 & 141746.56 \\
\hline IFM & $\begin{array}{l}\text { Reservoir capacity } \mathrm{m}^{3} / \text { population number } \\
\qquad\left(\mathrm{m}^{3} \text { per person }\right)\end{array}$ & 785 & 88 & 34 & 11 \\
\hline AWU & $\begin{array}{l}\text { Area of irrigated paddy fields / total paddy } \\
\text { fields } \times 100\end{array}$ & 155.90 & 105.20 & 19.90 & 26.90 \\
\hline WQM & $\begin{array}{l}\text { Achievement rate of objective water } \\
\text { quality/annual product per person }\end{array}$ & $77 \%$ & $75 \%$ & $74 \%$ & $90 \%$ \\
\hline SWR & $\begin{array}{l}\text { Billion } \mathrm{m}^{3} / \text { population number } \\
\left(\mathrm{m}^{3} \text { per person }\right)\end{array}$ & 7.02 & 5.87 & 18.55 & 9.06 \\
\hline WI & $\begin{array}{l}\text { Amount of annual water intake/annual } \\
\text { product per person }\left(\mathrm{m}^{3} / \text { Yuan }\right)\end{array}$ & 573 & 673 & 141 & 1335 \\
\hline $\mathrm{EB}$ & $\begin{array}{l}\text { Billions of kilowatt-hours / population } \\
\text { number (kilowatt-hours per person) }\end{array}$ & 3452 & 4775 & 5073 & 1474 \\
\hline
\end{tabular}

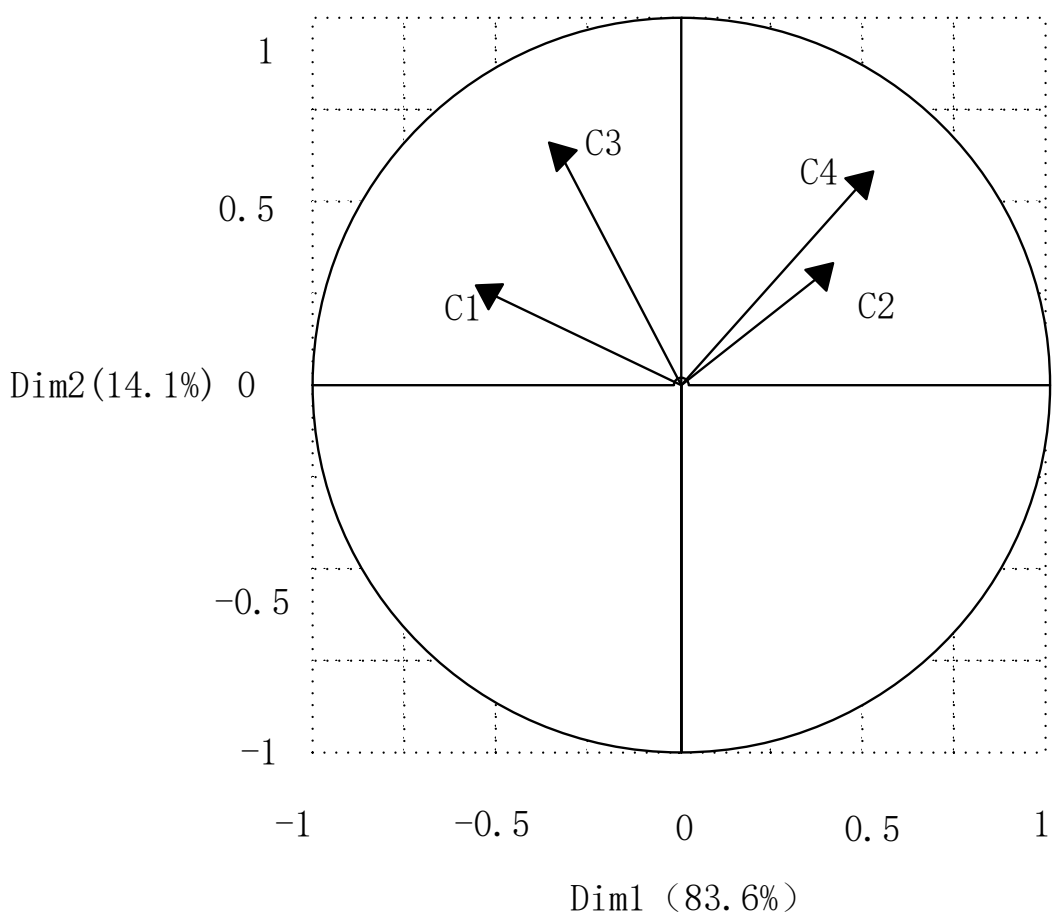

Figure A1. Circle correlation of PCA, where $\mathrm{C} 1$ represents environmental conservation, $\mathrm{C} 2$ represents maintenance capacity, C3 represents social equity, C4 represents economic efficiency. Data is the synthesis judgments from Table 8, variables are four criteria in this figure. 


\section{Appendix C Questionnaire Survey}

The survey was designed and conducted to determine indicator weights and importance priorities for assessment topics.

We are researchers from Huazhong University of Science and Technology, Wuhan, China. We would like to know your attitude towards the elements of water resources and sustainability assessment. Tick in the box after the option you want.

1. Gender Male Female
2. What is your name

3. What is your major occupation? : (a). Manager in environmental conservation; (b). Professor in water resources management; (c). Researcher in social equity; (d). Researcher in water resources development; (e). Professor in economics; (f). Other

4. For how long have you been in your job?: (a) 1-15 years; (b) 16-30 years; (c) 31 years and above

5. What is your level of education?: (a). Master; (b) Doctor; (c) Bachelor; (d) Other

6. You are asked to make comparative judgements on the relative importance of each pair of criteria below. A 9-point scale for measuring the relative importance of each criteria is adopted here for the pairwise comparison. 1 represents equal importance, 3 represents weak importance, 5 represents essential or strong importance, 7 represents demonstrated importance, 9 represents absolute importance.2, 4, 6 and 8 are intermediate values between the two adjacent judgements. Reciprocal values are assigned for each reversed pairwise comparison.

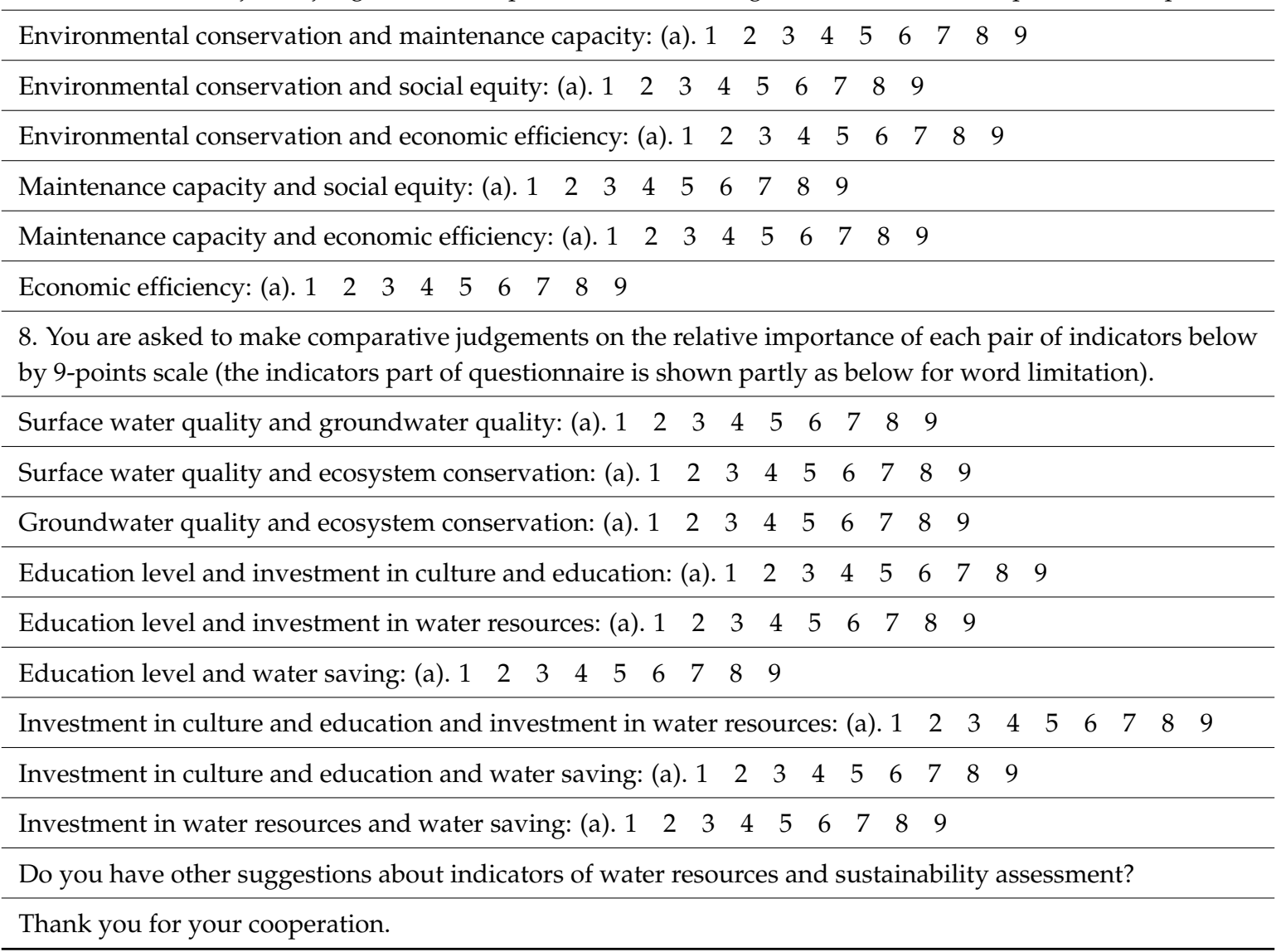

\section{References}

1. Wouters, P.; Rieu-Clarke, A. Sustainability criteria for water resource systems. Resour. Policy 2001, 27, 139-140. [CrossRef]

2. Abadi, L.S.K.; Shamsai, A.; Goharnejad, H. An Analysis of the Sustainability of Basin Water Resources using Vensim Model. KSCE J. Civ. Eng. 2015, 19, 1941-1949. [CrossRef] 
3. Milman, A.; Short, A. Incorporating resilience into sustainability indicators: An example for the urban water sector. Glob. Environ. Chang. 2008, 18, 758-767. [CrossRef]

4. Sun, S.K.; Wang, Y.B.; Liu, J.; Cai, H.J.; Wu, P.T.; Geng, Q.L.; Xu, L.J. Sustainability assessment of regional water resources under the DPSIR framework. J. Hydrol. 2016, 532, 140-148. [CrossRef]

5. Juwana, I.; Muttil, N.; Perera, B.J.C. Indicator-based water sustainability assessment-A review. Sci. Total Environ. 2012, 438, 357-371. [CrossRef] [PubMed]

6. Koop, S.H.A.; Cornelis, J.; Leeuwen, V. Assessment of the Sustainability of Water Resources Management: A Critical Review of the City Blueprint Approach. Water Resour. Manag. 2015, 29, 5649-5670. [CrossRef]

7. Giacomoni, M.H.; Berglund, E.Z. Complex Adaptive Modeling Framework for Evaluating Adaptive Demand Management for Urban Water Resources Sustainability. J. Water Resour. Plan. Manag. 2015, 141, 04015024. [CrossRef]

8. Xu, Z.X.; Takeuchi, K.; Ishidaira, H.; Zhang, X.W. Sustainability Analysis for Yellow River Water Resources Using the System Dynamics Approach. Water Resour. Manag. 2002, 16, 239-261. [CrossRef]

9. Zeng, X.T.; Li, Y.P.; Huang, G.H.; Liu, J. Modeling of Water Resources Allocation and Water Quality Management for Supporting Regional Sustainability under Uncertainty in an Arid Region. Water Resour. Manag. 2017, 31, 3699-3721. [CrossRef]

10. Peterson, H.M.; Nieber, J.L.; Kanivetsky, R.; Shmagin, B. Water Resources Sustainability Indicator: Application of the Watershed Characteristics Approach. Water Resour. Manag. 2013, 27, 1221-1234. [CrossRef]

11. Hernandez-Bedolla, J.; Solera, A.; Paredes-Arquiola, J.; Pedro-Monzonis, M.; Andreu, J.; Sánchez-Quispe, S.T. The Assessment of Sustainability Indexes and Climate Change Impacts on Integrated Water Resource Management. Water 2017, 9, 213. [CrossRef]

12. Ni, X.; Wu, Y.Q.; Wu, J.; Lu, J.; Wilson, P.C. Scenario analysis for sustainable development of Chongming Island: Water resources sustainability. Sci. Total Environ. 2012, 439, 129-135. [CrossRef] [PubMed]

13. Saaty, T.L. The Analytic Hierarchy Process; McGraw-Hill: New York, NY, USA, 1980.

14. Awang, A.; Ghani, A.T.A.; Abdullah, L.; Ahmad, M.F. Global Weights of Coastal Erosion Risk indicators using AHP Method: A Case Study of Setiu Wetlands. Natl. Symp. Math. Sci. 2017, 24, 050014.

15. Ishizaka, A.; Labib, A. Review of the main developments in the analytic hierarchy process. Expert Syst. Appl. 2011, 38, 14336-14345. [CrossRef]

16. Kang, M.G.; Lee, G.M. Multicriteria Evaluation of Water Resources Sustainability in the Context of Watershed Management. J. Am. Water Resour. Assoc. 2011, 47, 813-827. [CrossRef]

17. Shi, S.G.; Cao, J.C.; Feng, L.; Liang, W.Y.; Zhang, L.Q. Construction of a technique plan repository and evaluation system based on AHP group decision-making for emergency treatment and disposal in chemical pollution accidents. J. Hazard. Mater. 2014, 276, 200-206. [CrossRef]

18. Dragincic, J.; Milica, V. AHP Based Group Decision Making Approach to Supplier Selection of Irrigation Equipment. Water Res. 2013, 41, 782-791. [CrossRef]

19. Akaa, O.U.; Abu, A.; Spearpoint, M.; Giovinazzi, S. A group-AHP decision analysis for the selection of applied fire protection to steel structures. Fire Saf. J. 2016, 86, 95-105. [CrossRef]

20. Saaty, T.L.; Vargas, L.G. Dispersion of group judgments. Math. Comput. Model. 2007, 46, 918-925. [CrossRef]

21. Lin, S.W.; Lu, M.T. Characterizing disagreement and inconsistency in experts' judgments in the analytic hierarchy process. Manag. Decis. 2012, 50, 1253-1265. [CrossRef]

22. Palese, L.L. A random version of principal component analysis in data clustering. Comput. Biol. Chem. 2018, 73, 57-64. [CrossRef]

23. Yang, L.W.; Eyal, E.; Bahar, I.; Kitao, A. Principal component analysis of native ensembles of biomolecular structures (PCA_NEST): Insights into functional dynamics. Bioinformatics 2009, 25, 606-614. [CrossRef] [PubMed]

24. Bro, R.; Smilde, A.K. Principle component analysis. Anal. Methods 2014, 6, 2812-2831. [CrossRef]

25. Zheng, X.Q.; Nie, Y.; Gao, Y.; Huang, B.; Ye, J.H.; Lu, J.L.; Liang, Y.R. Screening the cultivar and processing indicators based on the flavonoid profiles of dry teas using principal component analysis. J. Food Compos. Anal. 2018, 67, 29-37. [CrossRef]

26. Longo, A.; Federolf, P.; Haid, T.; Meulenbroek, R. Effects of a cognitive dual task on variability and local dynamic stability in sustained repetitive arm movements using principal component analysis: A pilot study. Exp. Brain Res. 2018, 4, 1-9. [CrossRef] [PubMed] 
27. Sun, Z.Y.; Zhou, J.L.; Gan, L.F. Safety assessment in oil drilling work system based on empirical study and Analytic Network Process. Saf. Sci. 2018, 105, 86-97. [CrossRef]

28. Perez, M.; Tujchneide, O.; Paris, M.; Ela, M.D. Sustainability indicators of groundwater resources in the central area of Santa Fe province, Argentina. Environ. Earth Sci. 2015, 73, 2671-2682. [CrossRef]

29. Bradfor, A. An ecological flow assessment framework: Building a bridge to implementation in Canada. Can. Water Res. J. 2008, 33, 215-232. [CrossRef]

30. Spiller, M. Adaptive capacity indicators to assess sustainability of urban water systems-Current application. Sci. Total Environ. 2016, 569, 751-761. [CrossRef] [PubMed]

31. Zhang, J.; Bai, M.H.; Zhou, S.B.; Zhao, M. Agricultural Water Use Sustainability Assessment in the Tarim River Basin under Climatic Risks. Water 2018, 10, 170. [CrossRef]

32. Henriksen, H.J.; Troldborg, L.; Højberg, A.L.; Refsgaard, J.C. Assessment of exploitable groundwater resources of Denmark by use of ensemble resource indicators and a numerical groundwater-surface water model. J. Hydrol. 2007, 348, 224-240. [CrossRef]

33. Ercin, E.; Mekonnen, M.M.; Hoekstra, A.Y. Sustainability of national consumption from a water resources perspective: The case study for France. Ecol. Econ. 2013, 88, 133-147. [CrossRef]

34. Hoekstra, A.Y. The global dimension of water governance: Why the river basin approach is no longer sufficient and why cooperative action at global level is needed. Water 2011, 3, 21-46. [CrossRef]

35. Pellicer-Martinez, F.; Marnez-Paz, J.M. The Water Footprint as an indicator of environmental sustainability in water use at the river basin level. Sci. Total Environ. 2017, 571, 561-574. [CrossRef]

36. Almazán-Gómez, M.Á.; Sánchez-Chóliz, J.; Sarasa, C. Environmental flow management: An analysis applied to the Ebro River Basin. J. Clean. Prod. 2018, 182, 838-851. [CrossRef]

37. Vaidya, O.S.; Kumar, S. Analytic Hierarchy Process: An Overview of Applications. Eur. J. Oper. Res. 2006, 169, 1-29. [CrossRef]

38. Guo, J.W.; Zhou, M.C.; Li, Z.W.; Xie, H.G. Green design assessment of electromechanical products based on group weighted-AHP. Enterp. Inf. Syst. 2015, 9, 878-899. [CrossRef]

39. Jolliffe, I. Principal Component Analysis; Springer: New York, NY, USA, 2002; pp. 10-28.

40. Quiroga, J.; Mujica, L.; Villamizar, R.; Ruiz, M.; Camacho, J. PCA Based Stress Monitoring of Cylindrical Specimens Using PZTs and Guided Waves. Sensors 2017, 17, 2788. [CrossRef]

41. Saaty, T.L. Decision making with the analytic hierarchy process. Int. J. Serv. Sci. 2008, 1, 83-98. [CrossRef]

42. Song, M.B.; Li, T.X.; Chen, J.Q. Preliminary Analysis on Rainfall Runoff Features of Jinsha River Watershed. Procedia Eng. 2012, 28, 688-695.

43. Lidinska, L.; Jablonsky, J. AHP model for performance evaluation of employees in a Czech management consulting company. CEJOR 2018, 26, 239-258. [CrossRef] 